ten days of his illness ; afterwards Dover's powders and a diet of goat's milk. He had had no nausea, vomiting, cough, or symptoms referable to the chest or abdomen; the stools, two or three per diem, had been "porridgy"; there was no blood, mucus, or pain with movements of the bowels. His previous history elicited an eight months' residence in this country during which he had had many attacks of "fever"; one attack had been thought to be tick fever ; in the last attack, however, malarial parasites had been found. Previous to coming to this country he had been in South Africa for nine or ten years, and in 1901 had been treated in Bloemfontein Hospital for enteric fever, followed one week after discharge by dysentery with typical acnte symptoms, the attack lasting four weeks. Since then, till the present illness, he had had no returns of symptoms or diarrhoa.

On the evening of admission the blood was examined for malarial parasites and two only were seen, ring forms (malignant tertian), no crescents. The following five days quinine was given: 15 grains the first two days and then 20 grains as solution of bi-hydrochlorate. This had no effect on the temperature, which showed an evening rise, averaging $101^{\circ}$, and the pulse was from 66 to 88 per minute. The

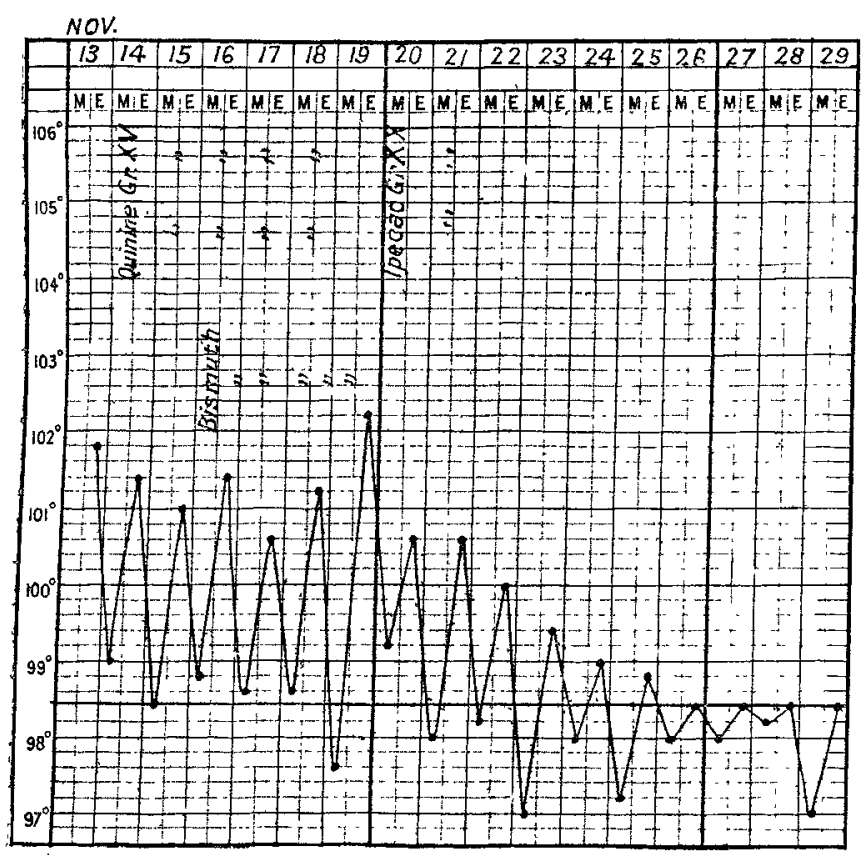

The complete chart also recorded a pulse frequency varying from 66 to 90 , generally keeping between 80 and 88 . The record of the evacuations showed " 2 loose" on the second day, "3 loose" on the third day, then "2 loose" with one intermission until the twelfth day, after which "I formed" is recorded daily with two intermissions. The diet is also described. "Nov. 13th: Milk, soda, chicken broth. Nov, 26th. Milk pudding bread and butter. Nov 28th.

Egg, toast, fish, potato. Dec. 1st : Chicken, duck."

urine was normal. There were two motions per diem, watery, with little fæcal matter, but neither mucus nor blood except on the second day after admission when what appeared to be a small old blod clot was passed. No improvement was effected by 20-grain doses of bismuth three times a day for three days. Microscopical examination of the stools proved negative as regards amœbæ. The tongue was thickly furred and the patient complained of weakness, headache, and profuse sweats in the evening. The spleen could just be felt; the liver showed no enlargement to percussion or tenderness to palpation; there avere no other physical signs in the chest or abdomen. At the end of the week, during which time no other malarial parasites had been found, quinine was discontinued and it was determined to try ipecacuanha. It was given in wafer, in 20-grain doses, on two consecutive days on an empty stomach, 20 minutes after a 20-minim dose of tincture of opium, as recommended by Manson. The result was immediate: the temperature commenced to fall, reaching normal in four days, and thereafter not rising again; the stools became more and more formed, being normal in three days; the tongue cleaned, and the patient expressed himself as feeling much better. The convalescence was uneventful, full diet being attained by the end of a week of normal temperature.

Major Rogers lays stress on a particular type of leucocytosis as being of value in making a diagnosis in these cases. Unfortunately, I was unable to make a "white count" till after the treatment had done its work-white cells then numbered 9000 per cubic millimetre. I think, however, that with the past history of dysentery the three weeks' pyrexia, immediately reacting to treatment by ipecacuanha, places this case among those that Major Rogers puts in Class IV. of his series, "Cases without Dysentery or Liver Symptoms treated with Ipecacuanha."

Blantyre, Nyasaland.

\section{A NOTE ON THE EXTRACTION OF FOREIGN} BODIES FROM THE TISSUES.

\section{By Hubert ChitTy, M.S. Lond., F.R.C.S. EnG.,} RESIDEN'T CASUAL''Y HOUSF, SURGEON, S'T. MARY'S HOSPITAL, PADDINGTON.

The following description applies only to the removal of those bodies which are opaque to the $x$ rays. The patient is taken into the $x$ ray room and the foreign body is roughly localised with the aid of a fluorescent screen. The area in which an incision will have to be made is then carefully cleansed and is infiltrated with a 1 per cent. solution of eucaine. A further examination of the part is now made with the $x$ rays. Guided by the shadows thrown upon the screen, the surgeon plunges the needle of the infiltrating syringe into the tissues till it touches and (in the case of a needle) lies as nearly as possible parallel to the foreign body. A few more drops of solution may now be injected and the syringe is then detached from its needle, which is left sticking into the part. This neerle is cut down upon and the incision necessarily exposes the foreign body at the same time.

Except where the foreign body lies very deeply it is often quicker to surround both it and the localising needle by an elliptical incision and to remove them both, together with a little skin and subjacent tissue, in one mass. The wound when closed by a stitch or two leaves no more scarring than does a linear incision.

I have chiefly used this method in cases of " needle in the hand," but it is, of course, equally applicable to the removal of glass, shot, \&c. It is rapid and certain, and the minimum of damage is inflicted on the soft parts. Strict asepsis is easily maintained, for, once the infiltrating needle has been brought into contact with the foreign body, no further screening of the part is required.

This plan for localising a foreign body is simpler and more accurate than any method of skin marking with which I am acquainted. Anyone who has had to hunt for small pieces of needle deeply imbedded in the muscles will appreciate its advantages.

St. Mary's Hospital, Paddington.

\section{attedical Socrietirs.}

\section{ROYAL SOCIETY OF MEDICINE.}

\section{MEDICAL SECTION. \\ The Tone of Cardiac Muscle.}

A MEETING of this section was held on June 23rd, Dr. D. B. LEES being in the chair.

Dr. A. M. Gossage read a paper on the Tone of Cardiad Muscle. He said that muscle was probably capable of two kinds of contraction - the ordinary twitch and "tone," and these might occur separately or in combination. Tone was never absent, so that the ordinary muscular contraction was superimposed on tone, but increase of tone diminished the size of that contraction; in other words, tone diminished contractility. Tone, unlike the ordinary muscle twitch, had no refractory period and was directly dependent on the strength of the stimulus. Tetanus was purely a phenomenon of tone. In cardiac muscle Porter had shown that tone diminished conductivity as well as contractility and it was probable that it also diminished excitability. Dilatation of the heart was due to loss of muscular tone and, as would be expected, was associated with increase of excitability, conductivity, and contractility. 